\title{
What do we know about the behavior of animal rabies in Chile trough the last years?
}

\author{
Raul Alegria-Moran¹, 2, 3 , Daniela Miranda', Alonso Parra ${ }^{4,3}$ and Lisette Lapierre ${ }^{1,3}$ \\ 'Department of Preventive Veterinary Medicine, Faculty of Veterinary and Animal Science, Universidad de Chile, Santiago, Chile; \\ ${ }^{2} \mathrm{PhD}$ Program in Agriculture, Forestry and Veterinary Science, Universidad de Chile, Santiago, Chile; ${ }^{3} \mathrm{Emerging}$ and Re-emerging \\ Zoonoses Research Network, Santiago, Chile; ${ }^{4}$ Unit of Zoonosis and Vectors, Department of Environmental Health, Ministerio de \\ Salud, Gobierno de Chile, Santiago, Chile
}

\section{Objective}

This study aims to analyze the evolution of the epidemiological behavior of rabies in Chile during the period 2003 to 2013, through the epidemiological characterization of a number of variables and description of spatial and temporal patterns of animal cases.

\section{Introduction}

Rabies is a zoonotic disease caused by an RNA virus from the family Rhabdoviridae, genus Lyssavirus. Worldwide distributed, control of rabies has been considered to be particularly amenable to a "One Health" strategy (1). In Chile, rabies was considered endemic in domestic dog population until the late 1960s, when a surveillance program was established, decreasing the number of human cases related to canine variants until the year 1972 (2). Rabies is recognized as a endemic infection in chiropterans of Chile and prompted the surveillance of the agent in this and other species (3).

\section{Methods}

An epidemiological characterization of the registered cases from the National Program for Prevention and Control of Rabies was carried. During the period 2003-2013, 927 cases were reported. Descriptive statistics and descriptive mapping, recording origin of the sample, number of cases per region, animal reservoir implicated and viral variant were performed. A spatial autocorrelation analysis was carried using Moran's I indicator for the detection of spatial clusters (4), using the Local Indicators of Spatial Association (LISA) statistics (5), at national and regional level of aggrupation (north, central and south zone). Temporal descriptive analysis was carried.

\section{Results}

927 positive cases were recorded. 920 (99.2\%) cases came from passive surveillance, while $7(0.8 \%)$ cases by active surveillance, total positivity was $77.02 \%$ and $1.37 \%$ respectively. Positivity was reported mainly in the central zone (88.1\%), mainly in Valparaiso (19.1\%), Metropolitana (40.6\%) (Figure 1), Maule (11.8\%) regions concentrated in urban centers. Main positive reservoirs were bats $(99.8 \%)$, specifically Tadarida brasiliensis and viral variant 4 was the most commonly diagnosed. LISA test gives a Moran's I indicator of 0.1537 $(\mathrm{p}$-value $=0.02)$ for the central zone (Table 1$)$. Rabies tend to decrease in fall and winter season ( 2.9 cases vs 13 cases during summer).

\section{Conclusions}

Wildlife rabies in bats remains endemic in Chile, concentrated in urban areas. The main reservoirs are insectivorous bats. There is a significant spatial autocorrelation of animal rabies cases in the central zone of Chile. Results are relevant to the design of preventive and control measures.

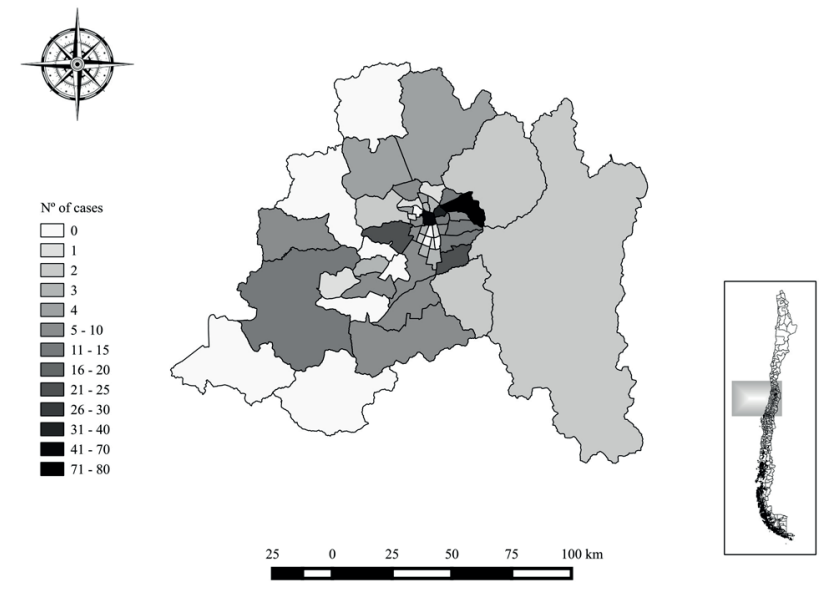

Figure 1. Choropleth map of the distribution of animal rabies in Metropolitana region, Chile, between the years 2003 and 2013.

\section{Keywords}

animal rabies; zoonotic diseases surveillance; one health; spatial autocorrelation

\section{Acknowledgments}

The authors acknowledge staff from the Rabies Laboratory from Instituto de Salud Pública (ISP), Chile.

\section{References}

1. WHO 2016. Rabies - Fact sheets, Media centre.

2. Favi, M. \& Durán, J. 1991. Epidemiología de la rabia en Chile (1929-1988) y perspectivas en mamíferos silvestres. Avances en Ciencias Veterinarias, 6.

3. Favi, M., Bassaletti, Á., López, J., Rodríguez, L. \& Yung, V. 2011. Descripción epidemiológica del reservorio de rabia en murciélagos de la Región Metropolitana: Chile. 2000-2009. Rev Chil Infectol, 28, 223-228.

4. Pfeiffer, D. U. \& Stevens, K. B. 2015. Spatial and temporal epidemiological analysis in the Big Data era. Prev Vet Med, 122, 213-220.

5. Pfeiffer, D., Robinson, T., Stevenson, M., Stevens, K., Rogers, D. \& 365 Clements, A. 2008. Spatial Analysis in Epidemiology, Oxford University Press.

${ }^{*}$ Raul Alegria-Moran

E-mail: ralegria@veterinaria.uchile.cl

Table 1. Moran's I index and p-value for the three macro-zones.

\begin{tabular}{|c|c|c|}
\hline Zone & Moran's I & $p$-value \\
\hline North & 0.0517 & 0.21 \\
\hline Central & 0.1537 & 0.02 \\
\hline South & -0.0117 & 0.34 \\
\hline
\end{tabular}

